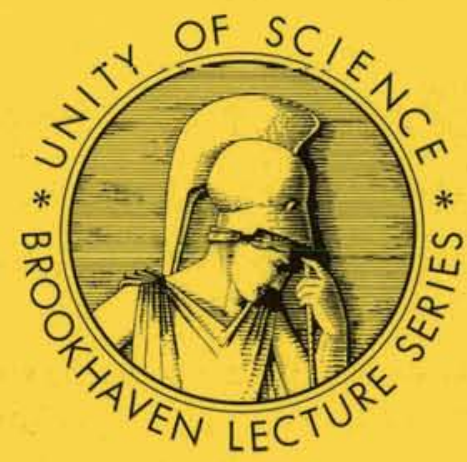

Number 57

May 18,1966

\author{
Associated Universities, Inc. \\ under contract with the \\ United States Atomic Energy Commission
}




\section{DISCLAIMER}

This report was prepared as an account of work sponsored by an agency of the United States Government. Neither the United States Government nor any agency Thereof, nor any of their employees, makes any warranty, express or implied, or assumes any legal liability or responsibility for the accuracy, completeness, or usefulness of any information, apparatus, product, or process disclosed, or represents that its use would not infringe privately owned rights. Reference herein to any specific commercial product, process, or service by trade name, trademark, manufacturer, or otherwise does not necessarily constitute or imply its endorsement, recommendation, or favoring by the United States Government or any agency thereof. The views and opinions of authors expressed herein do not necessarily state or reflect those of the United States Government or any agency thereof. 


\section{DISCLAIMER}

Portions of this document may be illegible in electronic image products. Images are produced from the best available original document. 


\section{FOREWORD}

The Brookhaven Lectures, held by and for the Brookhaven staff, are meant to provide an intellectual meeting ground for all scientists of the Laboratory. In this role they serve a double purpose: they are to acquaint the listeners with new developments and ideas not only in their own field, but also in other important fields of science, and to give them a heightened awareness of the aims and potentialities of Brookhaven National Laboratory.

Before describing some recent research or the novcl dcsign and possible uses of $u$ machine or apparatus, the lecturers attempt to familiarize the audience with the background of the topic to be treated and to define unfamiliar terms as far as possible.

Of course we are fully conscious of the numerous hurdles and pitfalls which necessarily beset such a venture. In particular, the difference in outlook and method between physical and biological sciences presents formidable difficulties. However, if we wish to be aware of progress in other fields of science, we have to consider each obstacle as a challenge which can be met.

The lectures are found to yield some incidental rewards which heighten their spell: In order to organize his talk the lecturer has to look at his work with a new, wider perspective, which provides a satisfying contrast to the often very specialized point of view from which he usually approaches his theoretical or experimental research. Conversely, during the discussion period after his talk, he may derive valuable stimulation from searchine " Jestions or technical advice received from listeners with different scientific backgrounds. The audience, on the other hand, has an opportunity to see a colleague who may have long been a friend or acquaintance in a new and interesting light.

The lectures are being organized by a committee which consists of representatives of all departments of the Laboratory. A list of the lectures that have been given and of those which are now scheduled appears on the back of this report.

Gertrude Scharff-Goldhaber

The drawing on the cover is taken from a 5 th Century B.C. relief on the Acropolis in Athens, the "Dreaming Athena," by an unknown sculptor. 
BNL 50005 (T-429)

(Health and Safety - TID-4500)

\title{
Health Physics Problems of High Energy Accelerators
}

\author{
F.P. COWAN
}

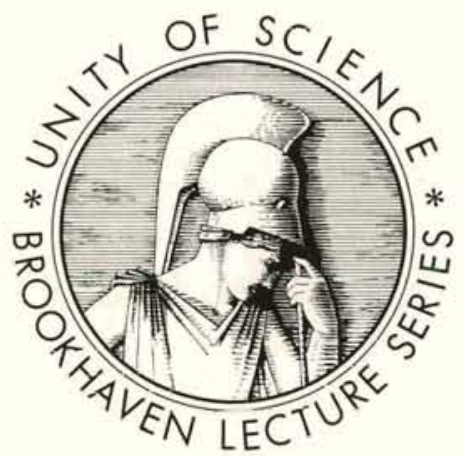

BROOKHAVEN LECTURE SERIES

Number 57, May 18, 1966 


\section{LEGAL NOTICE}

This report was prepared as an account of Government sponsored work. Neither the United States, nor the Commission, nor any person acting on behalf of the Commission:

A. Makes any warranty or representation, expressed or implied, with respect to the accuracy, completeness, or usefulness of the information contained in this report, or that the use of any information, apparatus, method, or process disclosed in this report may not infringe privately owned rights; or

B. Assumes any liabilities with respect to the use of, or for damages resulting from the use of any information, apparatus, mcthod, or process disclosed in this report.

As used in the above, "person acting on behalf of the Commission" includes any employee or contracror of the Commission, or employee of such contractor, to the extent that such employee or contractor of the Commission, or employee of such contractur prepares, disseminates, or provides access to, any information pursuant to his employment or contract with the Commission, or his employment with such contractor.

\section{Printed in the United States of America}

Available from

Clearinghouse for Federal Scientific and Technical Information National Bureau of Standards, U.S. Department of Commerce Springfield, Virginia 22151

Price: Printed Copy $\$ 3.00$; Microfiche $\$ 0.65$ 


\section{INTRODUCTION}

Contrary to what many of you may think, it did not take the occurrence of fatal injuries to awaken physicists to the fact that radiation is dangerous. In fact the radiation protection business started almost as soon as the radiation business. There was only about a six-month lag between Roentgen's report of his discovery and the first report of a definitely recognizable $x$-ray burn. The problem in the 20's and early 30 's was in some respects quite similar to the problem we are facing nowadays, except that we are now working in a somewhat different energy range. One problem was to find a suitable unit to express both $\mathrm{x}$-ray doses and doses from gamma rays of radium. There was considerable doubt about how to go about this instrumentally, and a bewildering array of units were in use or proposed.

There was not at that time a recognizable profession of health physics, and certainly the name hadn't yet been invented, but there were a fair number of physicists deviting essentially full time to what we would now call health physics: such people as Laurie Taylor, Robley Evans, L..F. Curtiss, Failla, and (somewhat later) Leo Marinelli in this country; Gray in England; Sievert in Sweden; and a group in Germany. There were also some rather peculiar ideas current; one of them was - and the German group was particularly strong on this - that not only the dose was important but the dose rate was extremely important. One proposed maximum permissible level was expressed as $10^{-5} \mathrm{R} / \mathrm{sec}$. In other words, if you got nice uniform dosage you could tolerate $0.8 \mathrm{R} /$ day, but you couldn't deliver this much except on a 24-hour basis. Fortunately this suggestion was not taken up very seriously, and the trend has been to lengthen the integration period (and at the same time to lower the accumulated dose) until we reached our present situation of integrating over a quarter or a year, depending on the level of operation.

In those days, as at present to some extent, the problem broke down into three parts: first, to devise some sort of instruments that would measure in a dependable fashion the radiation of interest, either in the laboratory or in the field; second, to determine some sort of units or common basis on which to standardize the instruments so that their readings could be compared; and third, to relate the observations of medical researchers and biologists on the biological effects of the radiations thus measured to effects of interest from the health standpoint. These three problems still exist, only now we are worrying about radiations in the $\mathrm{GeV}$ range instead of in the $\mathrm{keV}$.

Fred Cowan is somewhat a newcomer to the health physics profession but he has certainly done rather well. He is a native Yankee, born Down East and raised in Boston. He went to Bowdoin College, back to Harvard for his Ph.D., and later taught at RPI. During the war we were on opposite sides of the fence - he was in radar countermeasures, I was in radar and countercountermeasures. As a result we never got to know each other. Afterward he was for a while with the Chrysler Corporation, and then he came here to head up the Health Physics Division, which he has done ever since. He has been President of the Health Physics Society. He is a member of the American Board of Health Physics, the Board that certifies professional health physicists. He has been Chairman of the Board and Chairman of the Board's Examination Panel. He is a member of a great many committees, the most important being the International Committee on Radiation Units and Measurements (he is also on their Planning Board), and the International Committee on Radiation Protection, Committee III on External Exposure.

Dr. Cowan will talk about the problems of dose measurement and health physics problems in general around a high energy accelerator.

J.B.H. KUPER 


\section{Health Physics Problems of High Energy Accelerators}

- The subject of this talk is accelerator radiation safety, which is one of the most interesting and challenging aspects of the health physics program here at Brookhaven National Laboratory. However, before the discussion of the main topic, some preliminary explanation of the field of health physics in general may be appropriate. It is a broad one covering all aspects of radiation protection and, as such, is very much an interdisciplinary profession. Measurement of radiation dose and protection against radiation involve physics, engineering, and industrial hygiene. Waste disposal problems involve meteorology, geology, and oceanography. Analyses of environmental samples and human excreta involve chemistry, and the setting of exposure limits involves radiation biology and nuclear medicine. Nobody can be expected to be an expert on all these matters, so most health physicists know a little about most of them and more about the ones directly related to their local responsibilities.

The basic objective of a radiation protection program is to keep exposures below the specified limits with minimum interference with the accomplishment of assigned tasks, be they research or production. In addition, it is desirable to provide data useful in protecting the organization concerned against unwarranted suits and to avoid unnecessary exposures. In achieving these objectives, it is appropriate to establish rigid safeguards

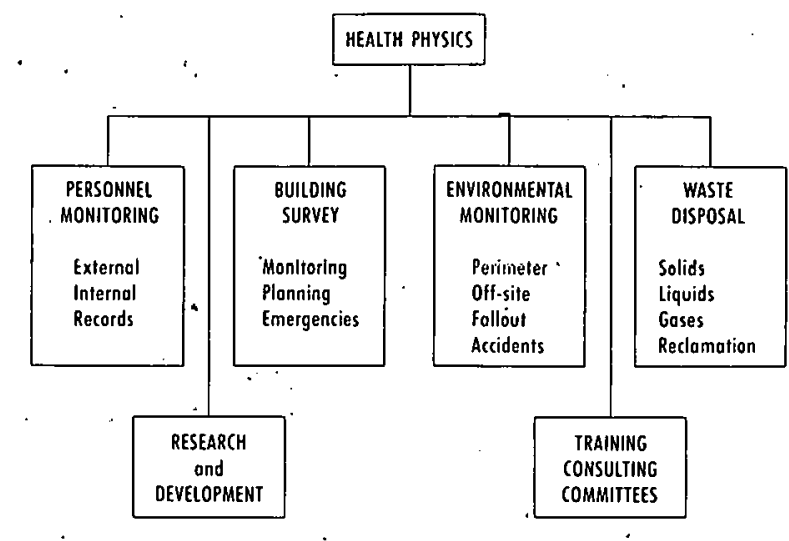

Figure 1. Health physics activities at. Brookhaven. for really dangerous situations and to arrange for comparatively loose control of clearly designated but not too hazardous areas. Of course, measurement of radiation levels and determination of the exposures actually received by people are of primary importance.

- The activities of health physicists may be very diverse, depending on local conditions. The scope of this profession may be judged from Figure 1, which shows the major activities at BNL broken down into several parts. The Personnel Monitoring Group measures external and internal exposures by means of film dosimeters and by processing urine samples, and keeps the central exposure records for the Laboratory. The Environmental Monitoring Group is concerned with the radiation levels outsidc the work areas, at the perimeter of the site, and off-site, due to fallout or to possible accidents or unscheduled release of radioactivity. The Waste Disposal Group gets rid of the solids, liquids, and gases that are contaminated with radioactive materials and therefore can't just be thrown out with the trash. It also carries out decontamination procedures and, in so doing, achieves a double objective: it makes things reusable and also makes it unnecessary to get rid of them. In addition, there is considerable training, consulting, and committee work, as well as some research and development work. The latter tends to be mostly of an applied nature and related to service activities.

The Building Survey Group is the backbone of the organization. The members of this group are the ones who go into individual areas and with

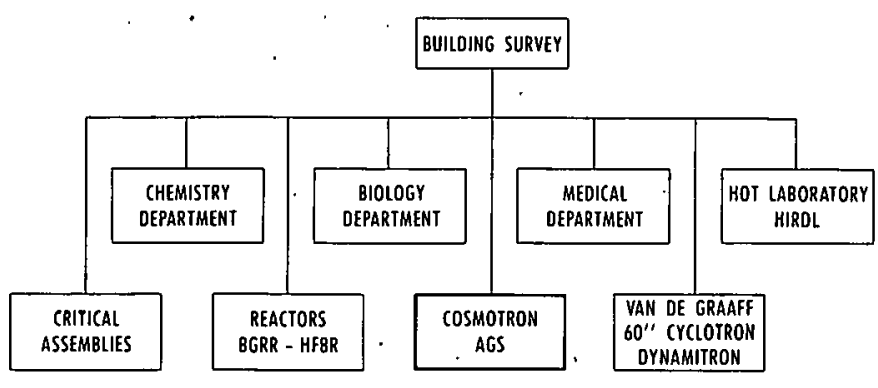

Figure 2. Major building survey locations at Brookhaven. 
whom most of you become personally acquainted. They do the monitoring, assist scientists and builders in planning facilities, and help cope with emergencies when they arise. Figure 2 shows somewhat more detail on this group. Small parts of it are in the various scientific departments and larger parts in the big facilities like the reactors, the Cosmotron, and the AGS. Since the rest of this lecture will be concerned with high energy accelerators, the Cosmotron-AGS location is emphasized in Figure 2, but the health physics problems at the other locations are diverse, interesting, and often quite challenging. Contamination and exposure control require continuing effort at the three reactors (BGRR, HFBR, and MRR), while exposure control is the major concern at the three Physics Department accelerators (Van de Graaff, 60-in. cyclotron, and Dynamitron). Other problems are encountered at the numerous vault, greenhouse, growth-chamber, and field irradiation facilities operated by the Biology Department; the Hot Laboratory, the High Intensity Radiation Development Laboratory, and the various critical assemblies operated by the Nuclear Engineering Department; as well as miscellaneous low level or tracer laboratories in several departments.

The synchrotrons are of special interest, not only because they are a major feature of the BNI, program but because they pose interesting and difficult problems in radiation dosimetry. I shall devote most of this lecture to these problems but would not like to downgrade the importance of practical exposure control in the use of these machines, especially the AGS. Because of the large areas involved, the numerous experimental groups, and the constantly changing modes of operation, complicated administrative control procedures and continual improvements in technique and protective arrangements are necessary. Unfortunately, there isn't time to describe in detail how these work out in practice. They are very interesting and constitute one of the immediate problems in carrying out the Laboratory's research programs.

\section{DOSIMETRY UNITS AND FACTORS}

Since biological damage results from the energy absorbed from radiation as it passes through the body, rather than from incident or transmitted energy, the concept of dose has been defined in terms of absorbed energy. The unit of absorbed dose is the rad, which corresponds to deposition of 100 ergs per gram of absorbing material. Biological effects depend on the type and energy of radiation as well as on the absorbed dose. $200-\mathrm{keV}$ $x$ rays have been chosen as a reference, and the comparative effectiveness of other radiations is described by means of a constant known as the "relative biological effectiveness" (RBE), which depends on the particular biological effect involved and other factors as well as on the type of radiation. For health protection purposes, it is necessary to choose a factor related to RBE that encompasses all effects and conditions of irradiation of practical importance for the exposure of people. Accordingly, the term dose-equivalent is used for the product of absorbed dose and various modifying factors chosen in such a way as to give a number proportional to an upper limit on possible adverse biological effects on humans. Dose-equivalent is defined as follows and its unit is the Rem (Roentgen equivalent man):

$$
\mathrm{DE}=\mathrm{D} \times \mathrm{QF} \times \mathrm{DF} \times \mathrm{OF},
$$

where

$$
\begin{aligned}
\mathrm{DE} & =\text { dose equivalent }(\text { Rem}), \\
\mathrm{D} & =\text { absorbed dose }(\mathrm{rad}), \\
\mathrm{QF} & =\text { quality factor } \\
\mathrm{DF} & =\text { distribution factor }, \text { and } \\
\mathrm{OF} & =\text { organ factor. }
\end{aligned}
$$

The quality factor takes account of the differences in biological effect among different types or qualities of radiation. These differences, at least to a first approximation, result from differences in the density of energy release along the path of ionizing particles, that is, the linear energy transfer (LET). The distribution factor takes account of the effect of non-uniform irradiation of the body, while the organ factor may be used for a particular organ that is more or less sensitive. The relationship between $Q F$ and LET recommended by the National Commission on Radiation Protection (NCRP) is shown in Figure 3.

\section{DOSIMETRY METHODS FOR ULTRA HIGH ENERGY RADIATIONS}

Figure 4 emphasizes the diversity of radiations that we have to cope with at ultra high energy machines. When a high energy proton in the $\mathrm{GeV}$ region from the AGS or the Cosmotron strikes a target, it produces a variety of secondary particles ranging all the way from protons and neutrons 
knocked out of the nuclei to three kinds of $\pi$ mesons produced in the interaction, as well as antiparticles, $K$ mesons, and hyperons, and a variety of other components that have less dosimetric effect. Figure 4 indicates the types of decay of the various products. The neutral pions produce $\gamma$ photons, the photons produce positive and negative electrons by the process known as pair production, and the electrons can produce more photons by the process that occurs in an $\mathrm{x}$-ray tube. If the primary particle has enough energy, the process can be repeated and an electron-photon cascade with many branches can result. The positive and negative pions decay into $\mu$ mesons, particles of a different type that interact very weakly with matter and hence are very penetrating. The $\mu$ mesons are especially important from a radiation protection point of view since, once formed by the decay

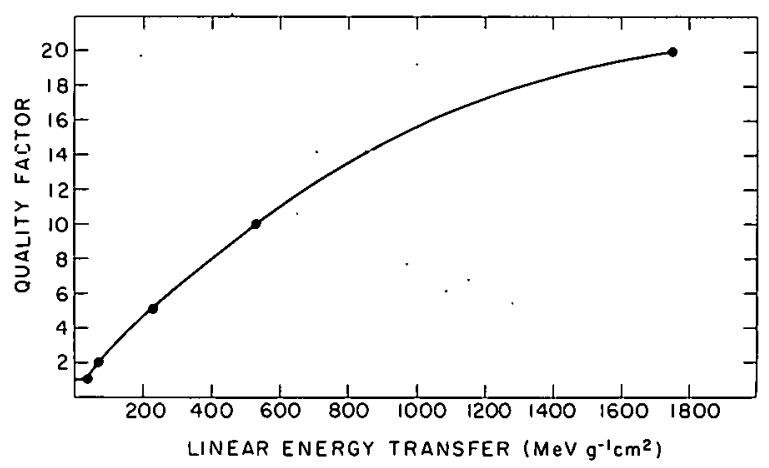

Figure 3. NCRP relationship between quality factor and linear energy transfer.

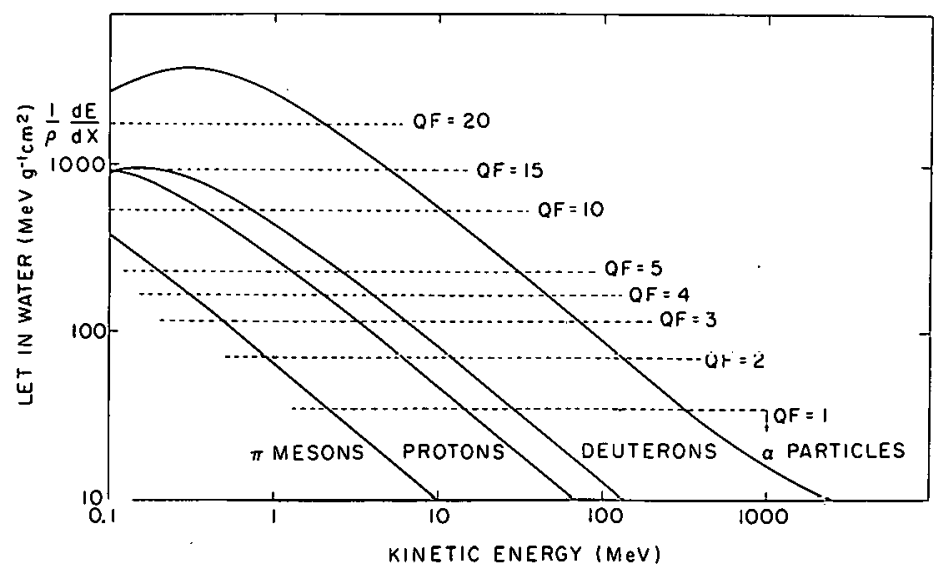

Figure 5. Relationship between LET and energy for various particles. of pions $\left(t_{1 / 2}=25.5 \mathrm{nsec}\right)$, they can be eliminated only by very thick shielding. Their decay products are electrons and neutrinos. Figure 4, then, is a simplified diagram of the nuclear processes and particles of greatest dosimetric importance.

Determination of the doses received by people in such a varied radiation environment can be a difficult task. The problem can be approached by two basic methods:

1. Determine the detailed composition of the radiation in terms of absorbed dose or flux values. Then establish factors converting each component to dose equivalent and thus deduce the total dose cquivalent.

2. Determine the LET spectrum of the radiation. Then deduce an average quality factor and compute dose equivalent from a measured value of absorbed dose.

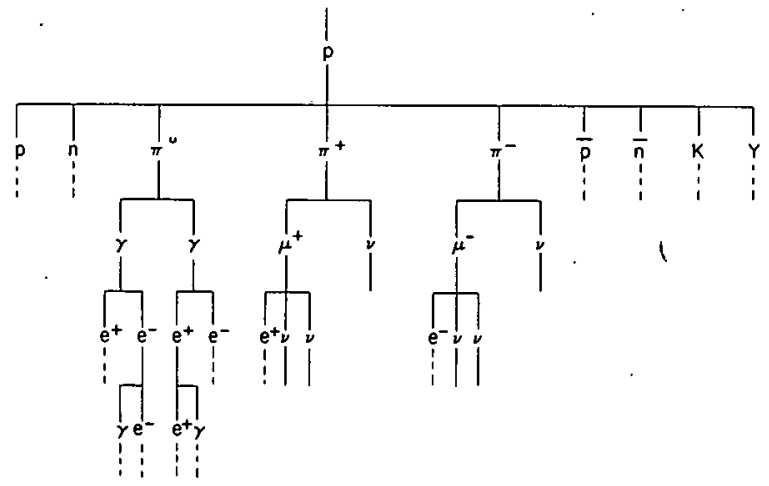

Figure 4. Secondaries from ultra high energy protons.

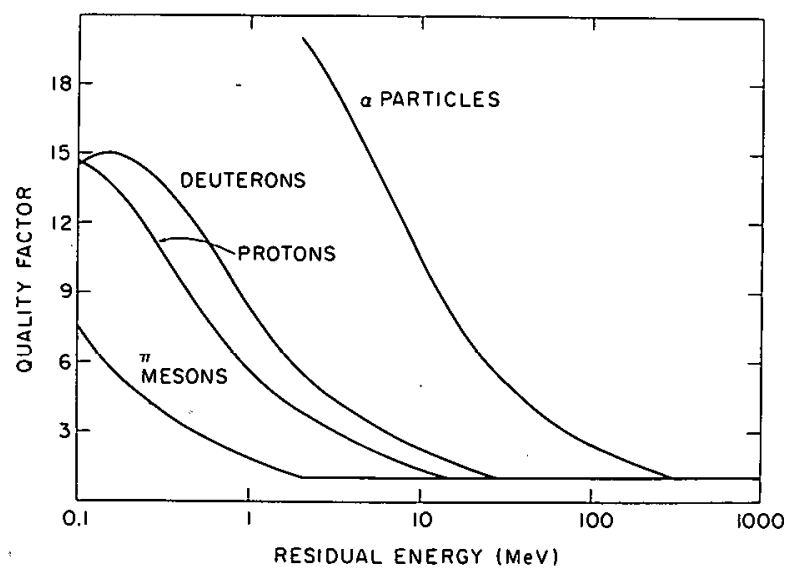

Figure 6. Relationship between quality factor and energy for various particles. 
The first method works well for low energy accelerators or well shielded ones of higher energy, since the radiation consists mostly of $\mathrm{x}$ or gamma radiation plus neutrons in the 0.5 to $10-\mathrm{MeV}$ range. The absorbed doses due to these two components may be measured separately, and a reasonably good conversion to DE can be made. At higher energies this method is difficult or impossible to apply, both because establishing the detailed composition of the radiations is a formidable task and because maximum permissible fluxes or quality factors for all the resulting components may not be available.

The second method does not require knowledge of the radiation composition, since to a first approximation different types of radiation having the same LET produce the same biological effects for a given absorbed dose. This is illustrated in Figure 5, which shows plots of LET vs. energy for several particles. The quality factors shown are those recommended by the National Commission on Radiation Protection (see Figure 3). Figure 6, derived from Figures 3 and 5, shows quality factor vs. energy for the same particles.

It is interesting that an extremely high energy proton, although relatively high in energy, is not relatively dangerous in terms of the quality factor because its track is so sparse that the quality factor is one.

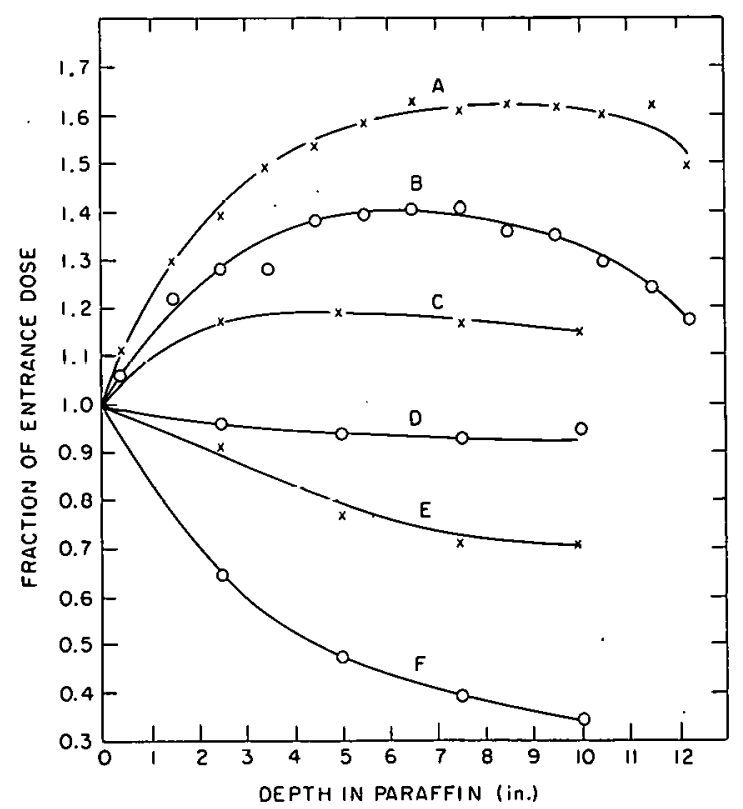

Figure 7. Buildup of dose in a phantom for typical AGS locations.
Regardless of the basic method used, account must be taken of the variation of dose with depth in the body. Dose may drop off with depth because of the effect of absorption, or it may increase because of the generation of secondary radiations as the primary radiation interacts with tissue. In practice, both effects occur simultaneously. Figure, 7 shows the variation with depth in a phantom observed at several AGS locations. These data were taken by Leigh Phillips when he made a study of this problem two years ago. There is a wide variation in behavior, but the buildup is seldom more than 1.6, and values as large as this are found only in relatively clean beams of high energy particles. For most locations where exposures to people are likely, buildup is slight or absent.

Variations in quality factor as a function of depth in the body should also be sought, and Phillips made some such measurements. Data obtained by Wheeler at the Argonne ZGS show the quality factor dropping off fairly steeply with depth in the body, but this must depend very much on circumstances, and it would be desirable to obtain more data under a variety of conditions.

These then are the basic dosimetry methods utilized at Brookhaven. They will be discussed in more detail in connection with instrumentation.

\section{GENERAL COMMENTS ON INSTRUMENTATION}

The ionization chamber shown at the right of Figure 8 is made of a plastic that approximates tissue in its atomic composition and is filled with a gas mixture that also approximates tissue. It provides a measurement of the absorbed dose whereever it is placed, but it must be remembered that this dose is an average over the volume of the chamber, for the population of existing secondaries, as modified by the chamber walls. This chamber was originally developed by Harald Rossi at Columbia University.

Figure 9 shows a portable ionization chamber which is used routinely to measure the dose around the machines. This one was developed by the BNL Instrumentation Division and has been extremely useful. The electrometer is located in a space just above the chamber. A problem is coming up in connection with this instrument. Our accelerators have always had a repetition period long enough so that one could look at one pulse on an instrument like this in the integrating mode and then reset to zero before the next pulse. How- 


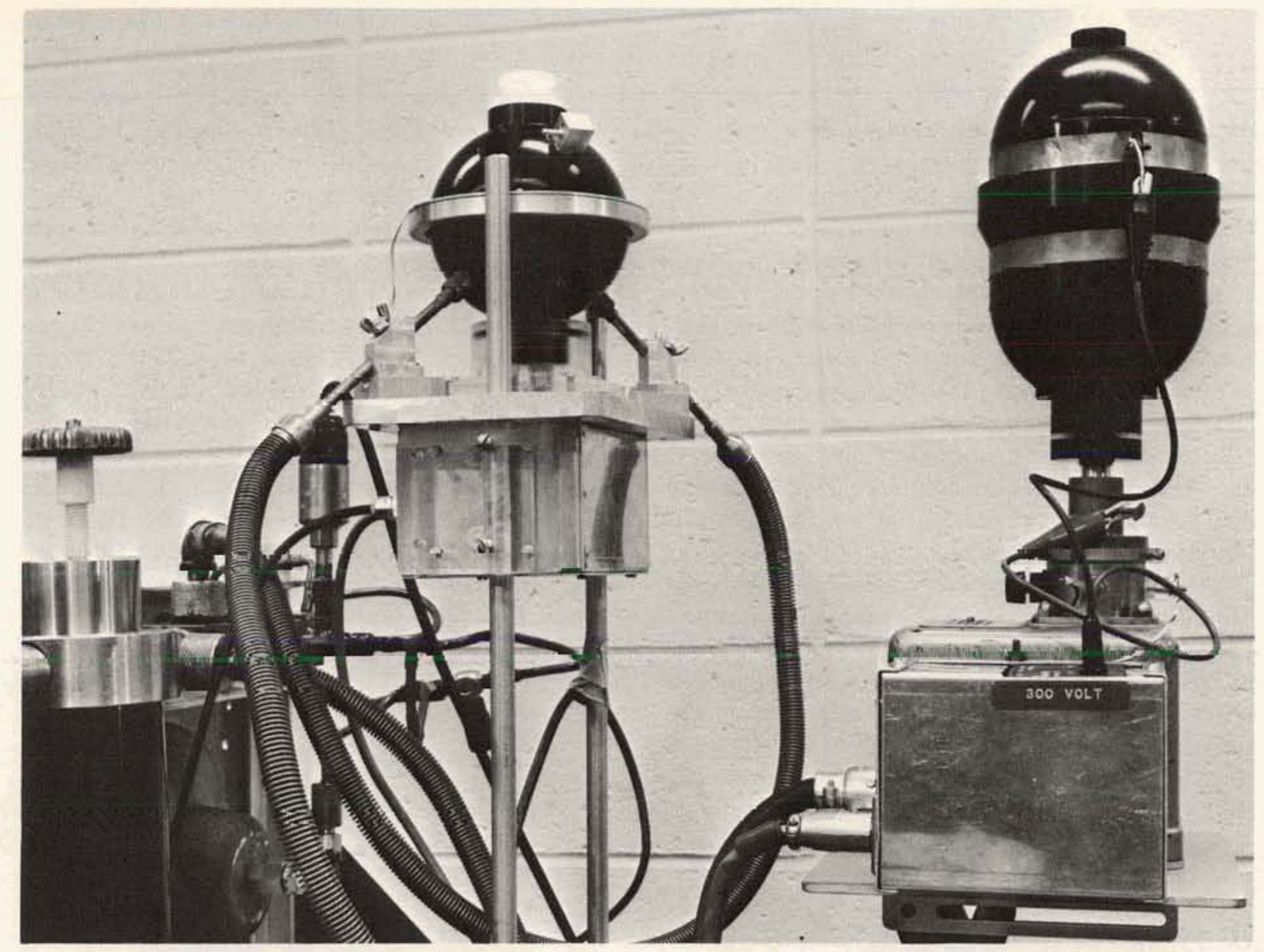

Figure 8. Ionization chambers for ultra high energy dosimetry.

Figure 9. Particle ionization chamber for Cosmotron and AGS surveys.

ever, the planned AGS conversion will result in a reduced repetition period too short for this type of measurement and a little too long for satisfactory rate meter operation. The instrument and the method of use will have to be modified for satisfactory operation under the new conditions.

The "integrating pulse discharge ionization chamber" (IPDIC) is a device that Carl Distenfeld, our health physicist at the AGS, unearthed and adapted for health physics service. It was being used for oilwell logging. He determined its characteristics and had it modified for our purposes, and it has been quite useful. The IPDIC is an ionization chamber lined with tissue equivalent plastic and filled with lissue equivalent gas at 10 atmospheres pressure (Figure 10). The outside is at ground potential, while the chamber wall is held at a fixed positive potential by a battery. The center electrode, initially near the ground potential, collects charge and increases in potential with respect to ground because of ionization until the internally

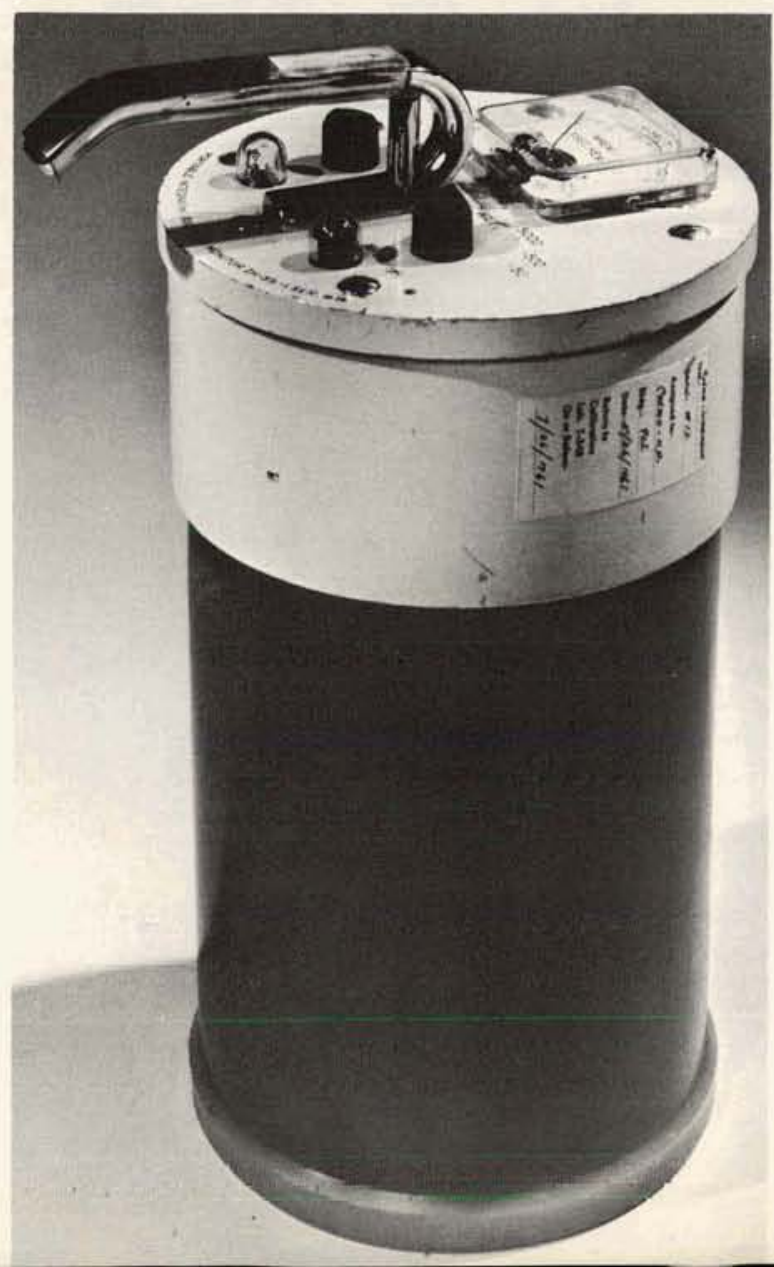


mounted neon tube discharges, thereby resetting the electrode to the relatively low potential at which the discharge stops. Every time this occurs, corresponding to a certain definite amount of dosage, a pulse, which can be of the order of 4 or 5 volts, is generated and operates the scaler. The insulation of this device is very good, and the prebreakdown current in the neon tube is less than the current due to natural background, so that this device can even be used for environmental monitoring. Figure 11 shows one such device used in a Cosmotron radiation monitoring system. These chambers have been used for other purposes also and have been quite satisfactory.

Several other measuring instruments are used around the accelerators. A thermal neutron detector placed inside a paraffin sphere makes a combination that measures neutron dose equivalent, crudely at least, over a limited energy range. Or one can use certain foils that have activation thresholds to determine the fluences (number per square centimeter) of particles above a certain energy, and thus get partial information about the type of radiation.

Of more interest are the two methods available for determining linear energy transfer, that is, the quantity that must be considered in choosing the quality factor needed to convert absorbed dose to dose equivalent.

\section{THE ROSSI METHOD OF LET ANALYSIS}

Dr. Harald Rossi at Columbia has developed a series of spherical tissue equivalent ionization chambers, with a special type of center electrode, by means of which one can determine the distribution of dose with respect to LET. Mr. Phillips has assembled an apparatus for this purpose at BNL, using a 4-in.-diameter chamber of this type, and has made numerous measurements at the BNL

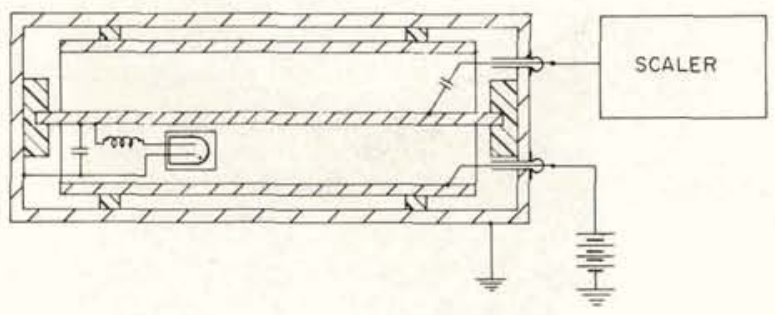

Figure 10. Integrating pulse discharge ionization chamber. synchrotrons. The chamber is seen at the left in Figure 8. Because of the spherical geometry, particles producing ionization tracks with a single value of LET give a triangular pulse-height spectrum, as shown at the left of Figure 12. For several discrete values of LET, the pulse-height spectrum is the sum of corresponding triangular distributions, as shown at the right of Figure 12. For continuous distributions of absorbed dose over a range of LET values, smooth pulse-height spectra, such as those shown in Figure 13, are obtained.

The information about the LET spectra is contained in the slopes of these curves. By determining the slope point by point and then using a suitable formula, one can determine the LET spectrum. Figure 14 shows the result of doing this for AGS location 2, for which the raw data are shown

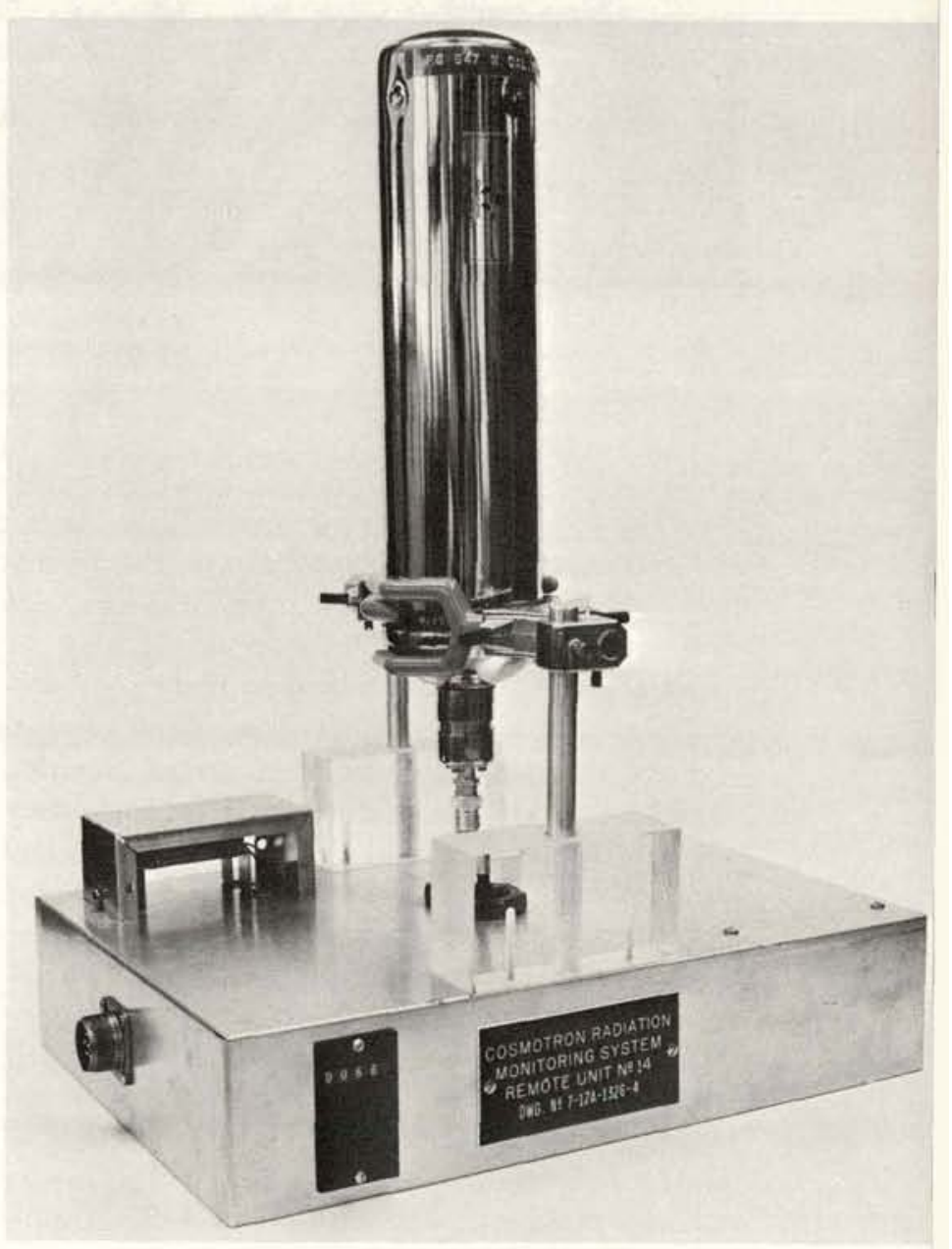

Figure 11. Detector for Cosmotron radiation monitoring system. 

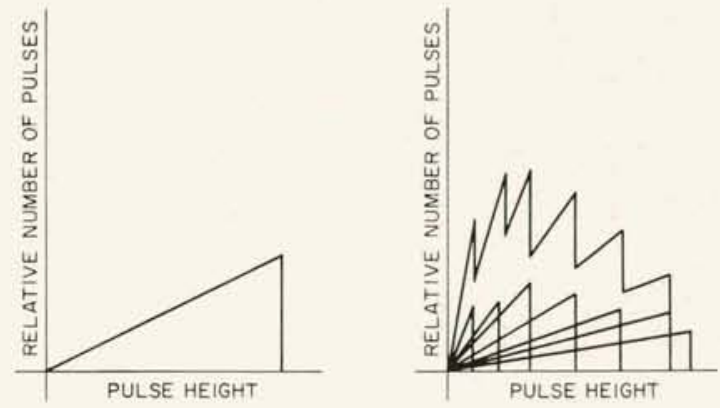

Figure 12. Pulse-height spectra with Rossi-type LET chamber for discrete values of LET.

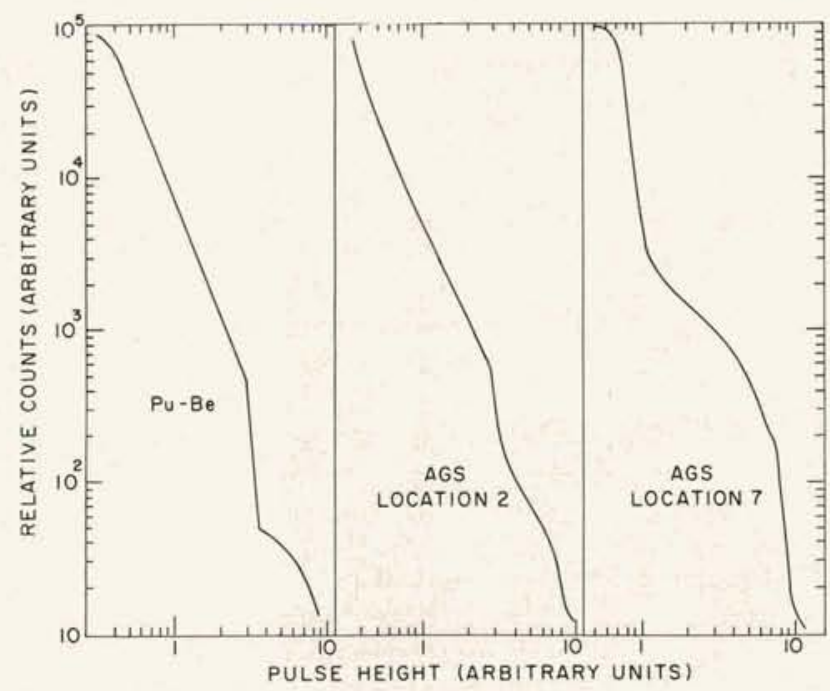

Figure 13. Pulse-height spectra obtained with the Rossi-type LET chamber.

in Figure 13. These data were obtained on top of the tunnel somewhat downstream from the G-10 target location. Two peaks are seen in the curve for absorbed dose. The one at the left corresponds to the so-called Bragg peak of the protons, namely, the region of denser ionization occurring near the ends of the proton tracks, whereas the one at the right is caused by heavy ion recoils that have produced tracks with much higher linear energy transfer. Figure 14 also shows the distribution of dose equivalent with LET. This is obtained by multiplying the absorbed dose distribution by the official relationship between quality factor and LET given in Figure 3 and shown by the dotted line in Figure 14. Values of total absorbed dose and total dose equivalent may be obtained by de-

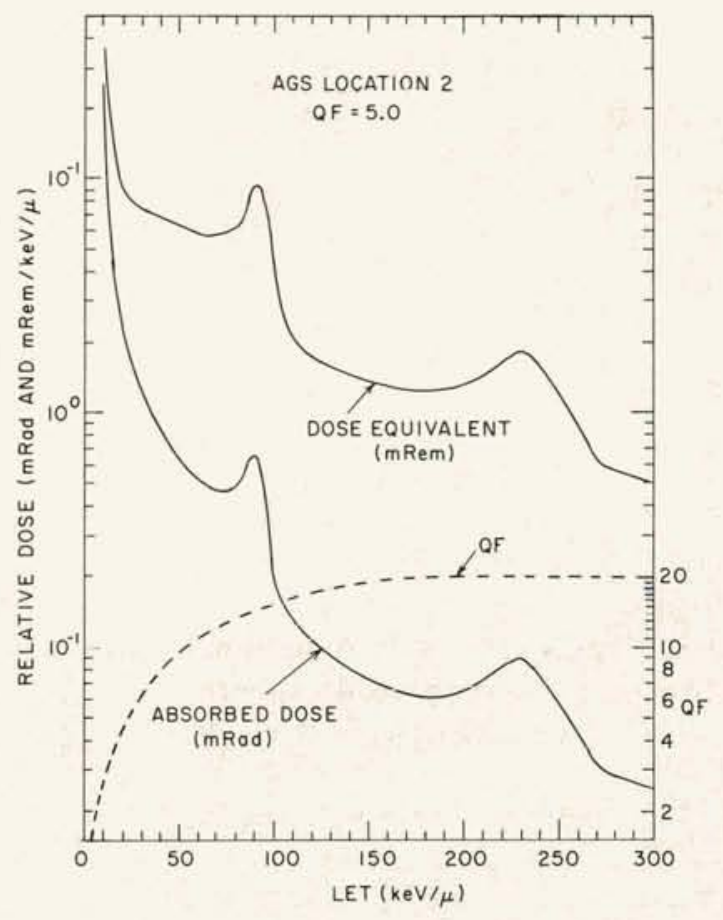

Figure 14. LET spectrum for an AGS location on top of the tunnel shield downstream from the G-10 target location.

termining the areas under the two curves. The effective quality factor for this particular mixture of radiation may be found by obtaining the ratio of these two areas; in this case it is 5.0. The data for this figure were taken at a location where, although the shielding is fairly thick, there are many high energy cascade components and therefore the quality factor is relatively high. Figures 15, 16, and 17 are included to show that the shape of the curves obtained may vary quite drastically, depending on the location at which data are obtained. Figure 15 is for a location where back-scatter from the G-10 target location predominates and the secondaries are quite well moderated. The Bragg peak at about $95 \mathrm{keV}$ per micron appears, but there is no appreciable peak corresponding to heavy ion recoils such as occurs in Figure 14. An intermediate value of quality factor is obtained. Figure 16 is for a location where $\mu$ mesons predominate. Since there are few protons, the peak at about $95 \mathrm{keV}$ per micron is absent as well as that due to high energy recoils. Figure 17 is for a $\mathrm{Pu}-\mathrm{Be}$ neutron source and is of interest because the neutron energy spectrum for such a source is well known.

Table 1 presents a summary of some of the effective quality factor values that have been ob- 


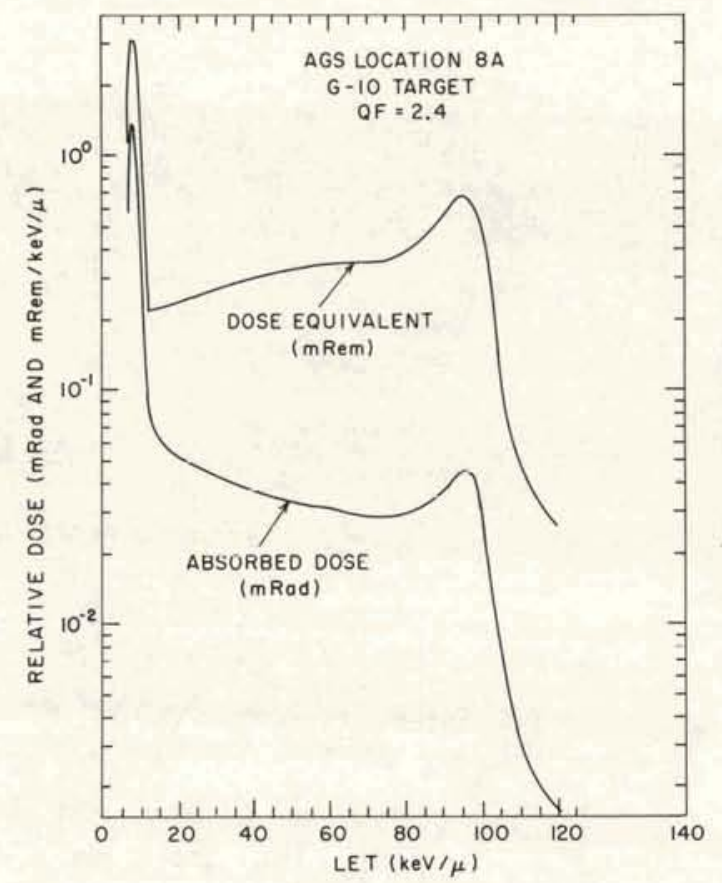

Figure 15. LET spectrum for an AGS location where back-scatter from the G-10 target predominates.

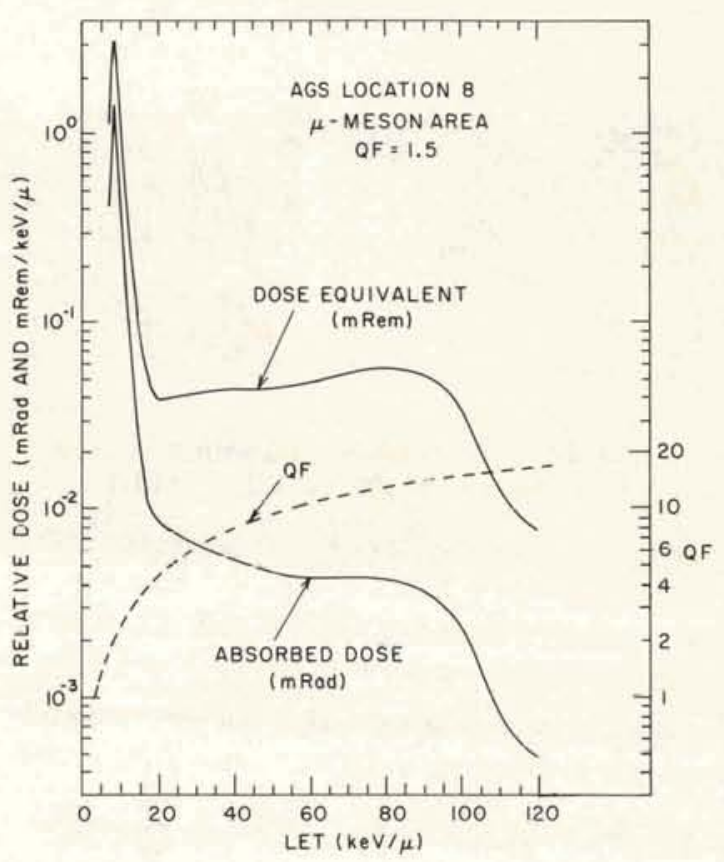

Figure 16. LET spectrum for an AGS location where $\mu$ mesons predominate.

Table 1

Summary of Quality Factors at the AGS Measured by the Rossi Method

\begin{tabular}{lll}
\hline AGS location & \multicolumn{1}{c}{ Description } & Quality factor \\
\hline 1 & Above G-10 target, $9 \mathrm{ft}$ heavy concrete & 4.3 \\
2 & Above G-10 target, $31 \mathrm{ft}$ downstream, heavy shielding & 5.0 \\
3 & $17-\mathrm{BeV} / c$ proton- $\pi$-meson beam & 1.7 \\
4 & Above $\mu$-meson area, F-10 target & 1.4 \\
5 & Outside north gate, $\mu$-meson, G-10 target & 1.3 \\
6 & Inside north gate, tunnel back-scatter & 4.2 \\
7 & Outside east gate, back-scatter from G-10 target & 2.4 \\
8 & $\mu$-Meson area 4 from F-9 target, heavy shielding & 1.5 \\
$8 \mathrm{~A}$ & $\mu$-Meson area, back-scatter from G-10 target $(\mathrm{F}-9$ target not in use) & 2.4 \\
$8 \mathrm{~B}$ & $\mu$-Meson area, $4^{\circ}$ from F-9 target, heavy shielding, 6 -in. paraffin phantom & 1.6 \\
\hline
\end{tabular}

tained. At the first two locations, since high energy secondaries are present, the effective quality factors are relatively high; whereas in the next three areas they are relatively low. The third location was in a beam consisting of protons and $\pi$ mesons. Although the particle energies were very high, the LET values were low because the beam was quite free of secondary components. At both the fourth and fifth locations, $\mu$ mesons, for which a quality factor of one is appropriate, were pre- dominant, so that the over-all quality factor was low. The F-10 target is located in such a way that the $\pi$ mesons generated in it have a substantial flight path before striking the tunnel shielding. Thus a sizable flux of $\mu$ mesons results from decay of the pions and, despite a very thick shield, there is an area outside where dosage is primarily due to $\mu$ mesons. However, one seldom encounters dosimetrically simple situations and this is no exception, since high energy components enter the area 


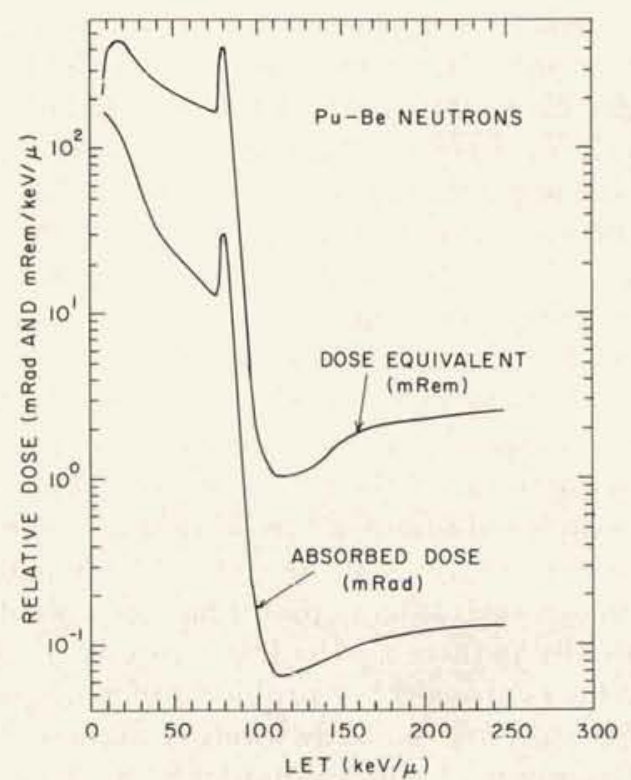

Figure 17. LET spectrum of Pu-Be neutrons.

from insufficiently plugged holes in the shield and by scattering of radiation that has penetrated the shield over the tunnel. The quality factors obtained for the other locations in Table 1 are also reasonably explainable in terms of the geometry of the individual locations.

\section{THE RECOMBINATION METHOD OF QUALITY FACTOR DETERMINATION}

If, for an ionization chamber which is being irradiated at a constant rate, current is plotted against the collecting voltage, a curve like that shown in Figure 18 is obtained. Above some voltage such as $V_{1}$, the ions are collected quickly enough so that recombination in the chamber as a whole does not occur. The curve is nearly horizontal above this so-called "saturation" voltage for radiation of low LET such as $\mathrm{x}$ or $\gamma$ rays. However, recombination of ions can still occur within the tracks left by more densely ionizing particles, and the degree of this columnar recombination is a function of LET. Thus the slope of the current-voltage characteristic in the "saturation" region may be used as an indicator of quality factor. The difference in current for two arbitrarily chosen collection voltages in the "saturation" region, such as $V_{1}$ and $V_{2}$, may be conveniently used as the actual indicator since it is proportional to the slope, $n$.

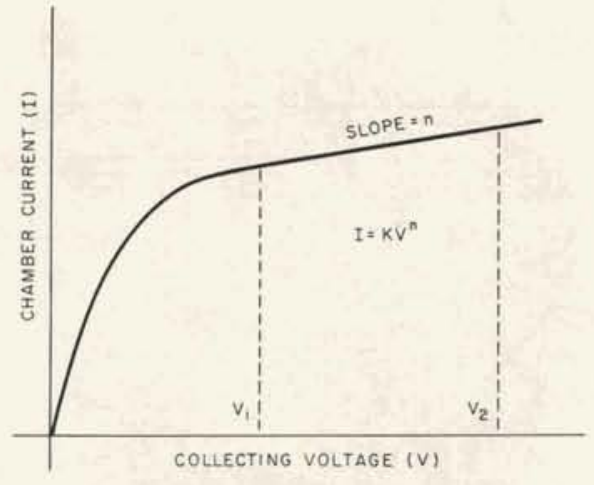

Figure 18. Current-voltage characteristic of an ionization chamber.

A Polish scientist named Zielczynski has reported the use of this method, and Baarli and Sullivan at CERN have developed it further. Distenfeld and Markoe here at BNL have built and evaluated a double chamber based on the same principle (Figure 19). Two ionization chambers are operated back to back, one at a considerably higher voltage than the other (300 and 1200 V). The balanced output circuit is adjusted to read zero for ${ }^{60} \mathrm{Co} \gamma$ radiation. For other types of radiation the deflection is approximately proportional to the departure of QF from a value of 1 . Figure 20 shows the actual apparatus constructed by Distenfeld and Markoe. It is heavy because it has to withstand 10 atmospheres pressure, but it is lined with plastic to make it reasonably tissueequivalent. Only a few measurements have been made with it but they agree reasonably well with those obtained by the Rossi method.

Although neither of these methods for direct determination of $\mathrm{QF}$ or $\mathrm{DE}$ is very satisfactory from a practical point of view, the results obtained with them have been very useful. Programs aimed at improving both these methods and developing new techniques for the same objective are being pursued at several laboratories including BNL.

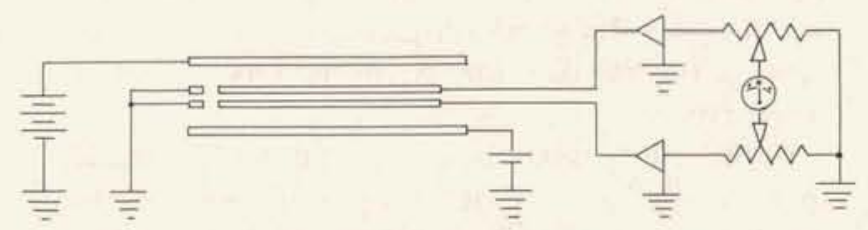

Figure 19. Schematic diagram of balanced tissue equivalent ionization chamber. 


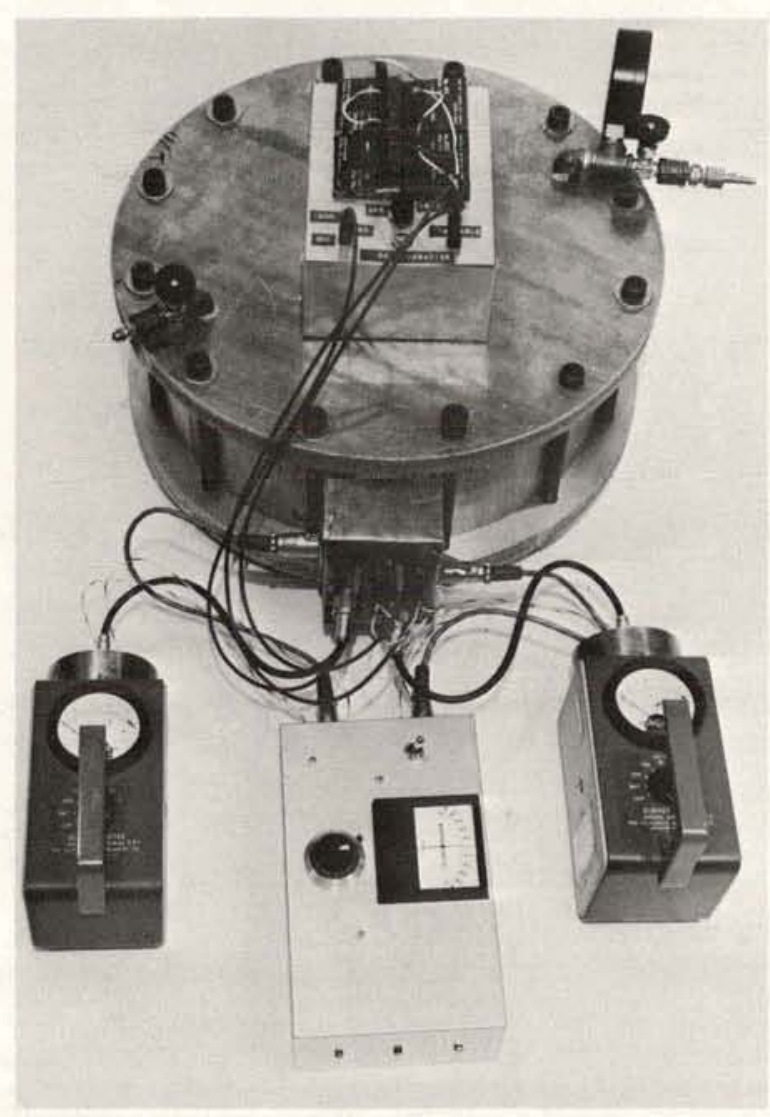

Figure 20. Balanced tissue equivalent ionization chamber for determination of dose equivalent.

\section{COMMENT ON CURRENT AGS PROBLEMS}

Measurements of effective quality factor have a substantial impact on personnel monitoring results. Our standard method of interpreting film badge data is designed to give results that are never too low, with ${ }^{60} \mathrm{Co}$ andPo-Be neutron sources used for calibration. When sizable exposures are being investigated, more sophisticated methods for determining the dose equivalent are utilized, and very frequently it is necessary to revise the routinely determined indicated dosages strongly downward. The time may be approaching when we can relax the standard quality factor applied to some of our measurements, on the basis of better information.

Some interesting measurements have been made on radiation levels in the surrounding areas due to skyshine. The AGS is well shielded, but in a few places radiation penetrates the shielding and scatters out around the surrounding countryside.
These levels are not high enough to be of any particular concern but would become so if the AGS intensity were increased by a factor of 20 or 30 as planned. It has been useful to measure levels from the existing machine and to extrapolate them to the expected higher intensity as a basis for the design of additional shielding. An interesting method for normalization of such data by radio has been developed by Distenfeld and Colvett.

The problem of personnel protection in the vaults and experimental areas is a continuing one during operation of the synchrotrons. Exposure control during shutdowns has become an increasingly serious business at the AGS. The machine has been too successful, in that it has been possible continually to increase the beam intensity, and this has accentuated the problems of activation and the associated exposure levels encountered in maintenance work during shutdown. Such maintenance work has been greatly increased by the radiation damage to machine components due to the increased intensity levels. To get this work done, it is necessary to schedule the work time of more than 200 individuals and to maintain detailed day-by-day records of their exposures. Thus far it has been possible to meet all requirements well below the specified exposure limits, but it has not been easy. The rebuilding of the machine will greatly improve the situation, but with the anticipated additional increases in intensity we cannot be sure whether or not the over-all results will be a net reduction of the unavoidable exposures.

\section{FUTURE PROBLEMS - HIGHER INTENSITY AND ENERGY}

One of the major future health physics problems in connection with high energy accelerators is the greater intensity planned. It is obvious that the problems of radiation levels in the experimental areas and activation of the machine and its components will increase as the power of the beam involved. If the particles have twice as much energy, it must be gotten rid of somewhere and it will result in radiation of one kind or another. Likewise, if the intensity in microamperes goes up, then there will be that much more energy to cope with. The beam power at the AGS is due to go up from 2.6 to $52.8 \mathrm{~kW}$ when the conversion program under way is completed, and that will increase the problems although the design is such as to solve 
Table 2

Beam Characteristics of Ultra High Energy Accelerators

\begin{tabular}{|c|c|c|c|}
\hline Machine & Current, $\mu \mathrm{A}$. & Energy, GeV & Power, kW \\
\hline Present AGS & $0.08\left(5 . \times 10^{11} \mathrm{p} / \mathrm{sec}\right)$ & 33 & 2.64 \\
\hline Converted AGS & $1.6\left(10^{13} p / \mathrm{sec}\right)$ & 33 & 52.8 \\
\hline Present SLAC & $30 \quad\left(1.9 \times 10^{14} \quad \mathrm{e} / \mathrm{sec}\right)$ & 20 & 600 \\
\hline Ultimate SLAC & $60 \quad\left(3.8 \times 10^{14} \mathrm{e} / \mathrm{sec}\right)$ & 40 & 2400 \\
\hline LAMPF & $1000 \quad\left(6.2 \times 10^{15} \mathrm{p} / \mathrm{sec}\right)$ & 0.8 & 800 \\
\hline Proposed $200 \mathrm{GeV}$ & $2.4\left(1.5 \times 10^{13} p / \mathrm{sec}\right)$ & 200 & 480 \\
\hline
\end{tabular}

many of them in the process of rebuilding. However, machines are being constructed with even higher beam powers, as shown in Table 2. The two-ruile long Stanford linear accelerator (SLAC), currently in the tune-up phase, is an example. This $30-\mu \mathrm{A}, 20-\mathrm{GeV}$ machine has a beam power of $600 \mathrm{~kW}$, which is much larger than the value for the AGS. The Stanford machine accelerates electrons, and, to a crude approximation, the radioactivity problems of electron machines are perhaps about a tenth those of proton machines for the same beam power. But the beam power of the SLAC can be increased in the future by a factor of 4 to a value of $2.4 \mathrm{MW}$.

At Los Alamos, construction is scheduled to start soon on a high intensity linear accelerator known as the Los Alamos Meson Physics Facility (LAMPF). It will produce $800-\mathrm{MeV}$ protons with a beam current of $1 \mathrm{~mA}$ corresponding to a beam power of $800 \mathrm{~kW}$. Since protons are involved, the radiation problems of operation and maintenance will be formidable.

The characteristics of the proposed $200-\mathrm{GeV}$ super-accelerator are also shown in Table 2. In this case, high beam power is combined with energy much higher than that of the present generation of proton synchrotrons, and some new and intensified problems are bound to be encountered. Machines with even higher beam powers are being seriously discussed by designers. Currents of 1- $\mathrm{GeV}$ protons up to $75 \mathrm{~mA}$, corresponding to a beam power of $75 \mathrm{MW}$, are being considered. There are exciting new applications for such machines, and they will present new challenges for health physicists.

Extremely high beam powers result in a whole covey of difficult and interesting design problemis, not only in the design of the accelerator structure itself but particularly in the design of the experimental areas. Not only is an external beam brought out of the machine for experimental purposes extremely hazardous, but the primary beam is so intense that the secondary beams scattered out of the machine for experimental purposes are comparable in hazard to the present deflected beams from the lower intensity machines.

Some of the design problems of the new high intensity accelerators are illustrated in Figure 21, which shows a cross section of the main tunnel of the $20-\mathrm{GeV}$ SLAC. The beam tube is in a separate tunnel under $25 \mathrm{ft}$ of earth shielding with as much of the auxiliary equipment as possible located in a building above. A similar design is proposed for the LAMPF but with the equipment gallery somewhat offset. In the case of the AGS conversion, equipment for the linac injector is to be housed in a building separated laterally from the main tunnel. At the SLAC, access to the main tunnel is via 35 -ft-long ladders, and these constitute a general safety problem of no mean proportions. Radiation levels in the equipment building are modest and due either to $x$ rays from the klystrons or radiation leaking up from below through ducts provided for the necessary electrical and vacuum line connections. Construction of the experimental areas for the SLAC is not yet finished. It is in these areas that some of the most difficult problems of exposure control will be encountered.

In connection with high intensity machines such as those at Stanford and Los Alamos, there are many other problems. Not only is adequate shielding necessary, but also the air inside the tunnel may become activated and so hazardous that access must be controlled for a period after shutdown. At Stanford the tunnel is closed up and not ventilated at all during operation to prevent the pumping out of radioactive air that would float across the countryside and perhaps be of some concern. It is by no means certain that this is absolutely necessary, but it is one method of control, 


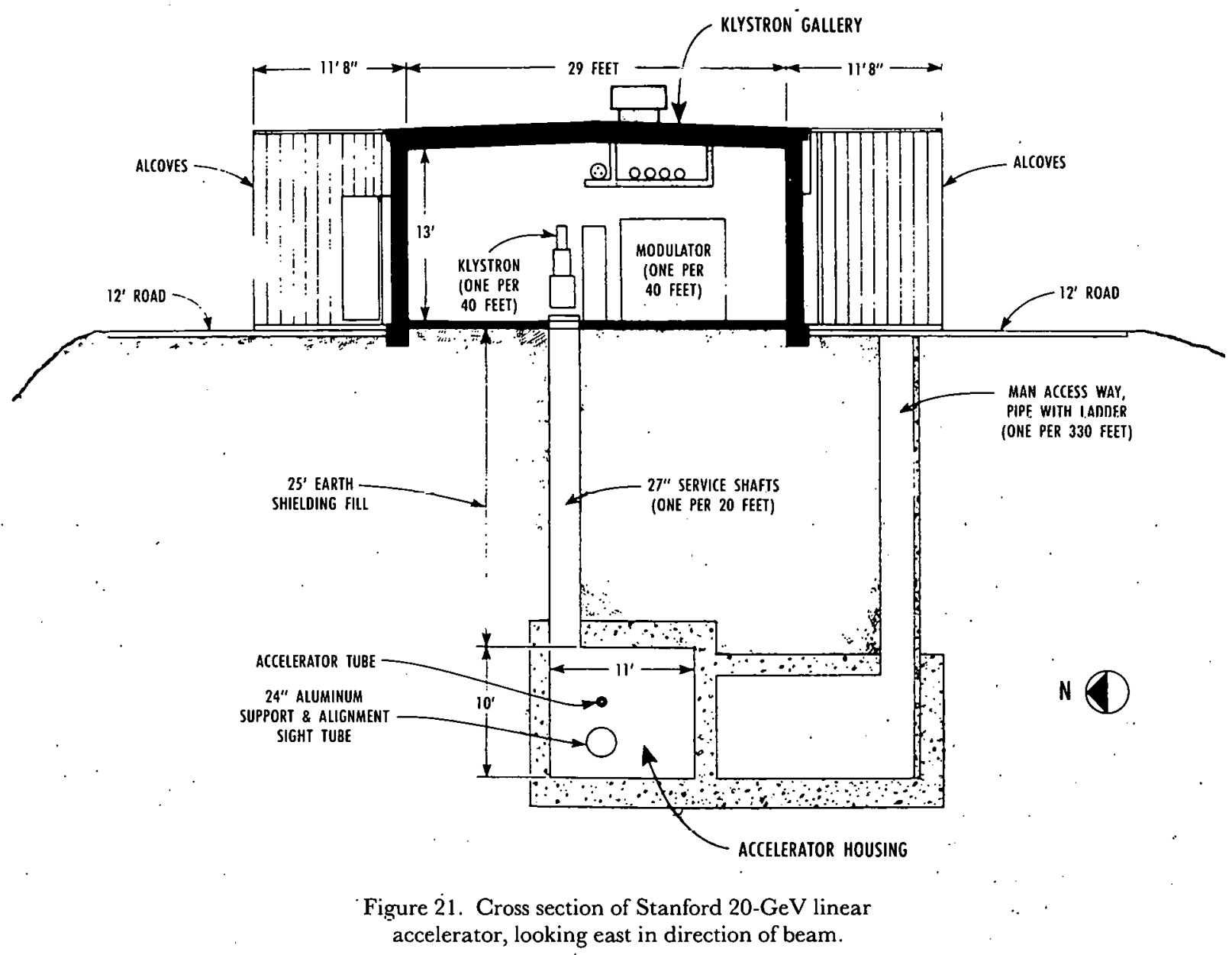

although some corrosion problems due to insufficient ventilation have been encountered.

After the experimenters finish with a high intensity beam, it must be stopped somehow or other. This calls for beam catchers, and the design of such devices is not simple because of the large amount of heat that must be dissipated and the huge amounts of radioactivity produced. Not only is radioactivity induced in solids used in the catcher, but water used for cooling becomes very radioactive. Thousands of curies of tritium, which is a prominent spallation product, and tens of thousands of curies of activation products of intermediate half-life build up in cooling water after extended periods of operation, so there must be considerable concern about the fate of this water. This involves arrangements for ultimate disposal of the activity and safeguards to prevent contamination of experimental areas or the groundwater in case of leaks or other accidents. Concern for water activation may even extend to rain water that may seep down close to the beam tunnel where neutron fluxes are high and where the resulting production of activity may cause groundwater contamination.

\section{FUTURE PROBLEMS - INSTRUMENTATION}

Some improvements in instrumentation would be highly desirable. First, a better method of personnel monitoring is greatly needed. At present, nuclear track film is used, but the statistics are very poor, the sensitivity is too low, and the film has an undesirable energy response characteristic. It would be very useful to have a personnel monitoring method that would give values of dose equivalent regardless of the kind of radiation involved. The situation is the same in regard to survey meters. It would be convenient to have a black box that would register, wherever it was placed, dose equivalent for any type of ionizing radiation. Such an instrument is not inconceivable. For in- 
stance, if the Rossi LET chamber could be made to operate as a sealed unit without the present complicated gas supply and vacuum system, an electronic circuit might be devised that would provide a reading directly as dose equivalent. Several difficulties remain to be overcome in the development of such an instrument, but most of the necessary ideas have been put forward, and there is reason to hope that a practical unit of this type will become available before too long.

\section{OTHER FUTURE PROBLEMS}

Continuing progress is needed in reduction of exposures incurred in operattng and maintinining the big accelerators. Exposure control is a major problem during shutdowns and, as emphasized above, will become even more so with the higher intensities that are coming.

An interesting new problem has to do with possible exposures to passengers and crews of the next generation of commercial aircraft, supersonic planes that will fly at elevations of 75,000 to $80,000 \mathrm{ft}$. At that elevation, if there is a large solar

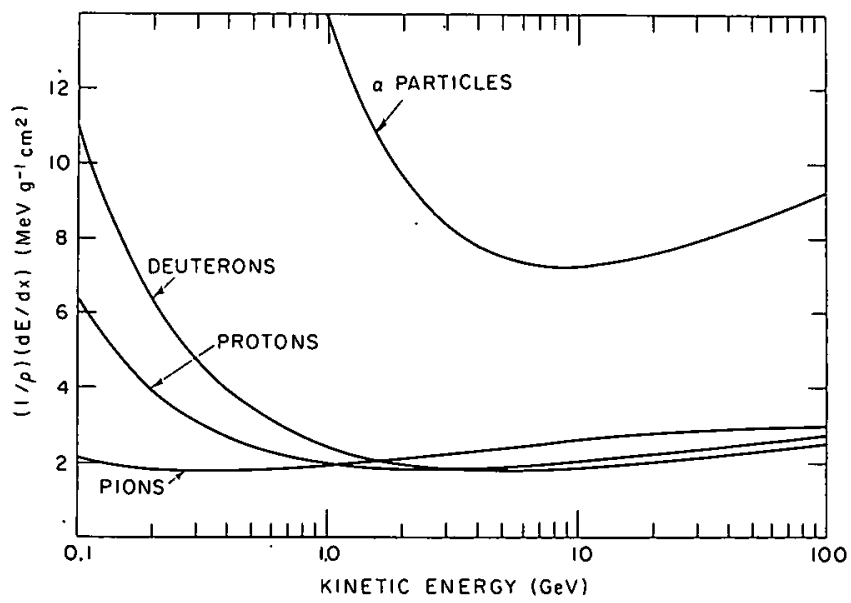

Figure 22. LET of particles in ultra high energy range.

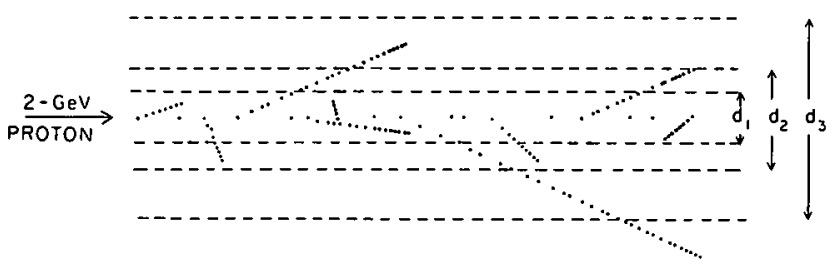

Figure 23. Electronic interaction of an ultra high energy proton. flare, the plane will be bombarded by particles from the sun and exposure will reach levels above those normally permitted for the populace at large. Several plans are being developed for instruments to be carried on the plane to measure these levels. If abnormal levels of dose rate are encountered, the pilot can descend to $40,000 \mathrm{ft}$ where exposure levels are lower. One of the things that make the field of health physics interesting is that one frequently becomes involved with curious new and yet scientifically intelligible problems, such as the dosimetry and exposure control problems associated with high altitude flight and space travel, which will require a great deal of attention in the fulue.

It would be very helpful if the official curve relating quality factor and linear energy transfer shown in Figure 3 could be extended to both lower and higher values of LET. Biological experiments indicate that relative biological effectiveness ratios less than one are found for very low values of LET such as exist along the tracks of ultra high energy protons. Figure 22 shows plots of mass stopping power (approximately equal to LET) in the reginn from 0.1 to $100 \mathrm{GeV}$. At present, a quality factor of one is used for all LET values of less than $35 \mathrm{MeV} \mathrm{g}^{-1} \mathrm{~cm}^{2}$. In the ultra high energy region values for pions, protons, and deuterons are much lower than this, and even in the case of $\alpha$ particles low values occur above one $\mathrm{GeV}$. It would be quite helpful, in designing instruments which read out in dose equivalent on the basis of LET values, if the discontinuity in the official curve at $35 \mathrm{MeV}$ $\mathrm{g}^{-1} \mathrm{~cm}^{2}$ could be removed.

A somewhat similar situation exists for high values of LET. At present the curve of Figure 3 reaches a high value of 20 for $Q F$, but no values are recommended for values of LET greater than $1750 \mathrm{MeV} \mathrm{g}^{-1} \mathrm{~cm}^{2}$. Many biological experiments, especially those made at the Berkeley HiLac, indicate that relative biological effectiveness passes through a maximum for LET values of 500 to $1000 \mathrm{MeV} \mathrm{g}^{-1} \mathrm{~cm}^{2}$, and that for extremely high values, $R B E$ may even become less than one. Such a behavior is explained on the basis of energy being wasted ino overkilling the cells traversed by such an extremely dense track of ionization. Here again, extension of the curve would be very helpful both in designing instruments and in assessing the importance of exposure components caused by such densely ionizing particles. However, extension of the curve in the high LET direction in- 
volves a consideration of many complicating factors, and I doubt if present understanding is sufficient to warrant official action, at least for the present.

Another basic problem worthy of future study is illustrated in Figure 23, which is a simplified drawing of the track of a $2-\mathrm{GeV}$ proton passing from left to right. Ionization along the track is very sparse but there are occasional $\delta$ rays of comparatively low energy which make secondary ionization tracks typical of low energy electrons. The diagram is idealized because low energy electron tracks are not straight but wander around a great deal because of the ease with which particles can be scattered. One of the interesting problems in radiation biology may be phrased as follows: Is the relative biological effect or the related quality factor best described by a linear energy transfer value that includes all energy out to an infinite distance from the track, or would it be better described by the energy released in a tube of some specific diameter enclosing the region near the track where the densest ionization occurs? Dr. Rossi at Columbia is studying this problem by means of his LET chambers. The one that we have been using operates at a sufficiently reduced pressure so that it corresponds to a tissue sphere of about onemicron diameter. However, Rossi has constructed a series of spheres with different diameters including much smaller ones and hopes to accumulate experimental evidence that will help answer the above question. This work also bears intimately on an understanding of the detailed mechanism of the damage of tissue by radiation and on why there is a variation of this damage with linear energy transfer. 


\section{LIST OF BROOKHAVEN LECTURES (Continued)}

(Those with BNL numbers have been published or are in press)

38. "Hot Atoms" and Their Reactions With Organic Compounds Alfred P. Wolf, Chemistry Department June 17, 1964

39. Chemical-Biochemical Signal and Noise Resolution at Low Temperature, BNL 893 Simon Freed, Chemistry Department September 23, 1964

40. Oriented Nuclei, BNL 903 Vance L. Suilor, Physics Department

October 14, 1964

41. The Gases of the Blood, BNL 898 Donald D. Van Slyke, Medical Department

November 18, 1964

42. Mechanism of the Immune Response, BNL 912 Marian Elliott Koshland, Biology Mepartment

December 9,1964

43. Ihe Ordered-Bed Breeder Reactor, BNL 50044 Warren E. Winsche, Nuclear Engineering Department January 20, 1965

44. Talking to Computers John E. Denes, Applied Mathematics Department February 24, 1965

45. Radiation and the Patterns of Nature, BNL 924 George Woodwell, Biology Department

March 24, 1965

46. Passage of Charged Particles Through Crystal Lattices, BNL 944 Cavid Erginsoy, Physics Department April 21, 1965

47. Chemical Crystallography, BNL 930 Walter C. Hamilton, Chemistry Department

May 12,1965

48. Extracorporeal Irradiation of the Blood and Lymph in the Study of Normal Leukemic Cell Proliferation Eugene P. Cronkite, Medical Department

June 23,1965

49. Neutrons as Magnetic Probes, BNL 946 Robert Nathans, Physics Department

September 29, 1965

50. Symmetry Principles in Physics, BNL 956

C.N. Yang, Institute for Advanced Study, Princeton

October 13, 1965

51. Defects in Crystals, BNL 952

G.J. Dienes, Physics Departmenl

November 17,1965

52. Genetic Tobacco Tumors and the Problem of Differentiation, BNL 967 H.H. Smith, Biology Department

December 15, 1965
53. Nuclear Methods in Art and Archaeology Edward V. Sayre, Chemistry Department

January 19,1966

54. Molecular Storage of Biological Information Leonard D. Hamilton, Medical Department

February 16, 1966

55. Early History of Associated Universities and Brankhaven National Laboratory, BNL 972 Norman F. Ramsey, Harvard University

March 30, 1966

56. Gamma Rays for Fun and Profit Bernard Manowitz, Nuclear Engineering Department April 20, 1966

57. Health Physics Problems of High Energy Accelerators, BNL 50005

$$
\begin{aligned}
& \text { F.P. Cowan, Instrumentation } \\
& \text { and Health Physics Department }
\end{aligned}
$$

May 18,1966

58. Some Mechanisms of Meson Creation Edward 0. Salant, Physics Department

June 29,1966

59. Dynamic Structure of Liquids Arthur Paskin, Nuclear Engineering Department September 28, 1966

60. The Hunting of the Quark - The Fundamental Nuclear Particle? Robert K. Adair, Accelerator Department October19, 1966

61. Ion-Molecule Collision Processes Lewis Friedman, Chemistry Department

November 22, 1966

62. Energy Conversion in Photosynthesis, BNL 50051 John M. Olson, Biology Department January 11,1967

63. The Cellular Basis of Radiation Death Victor P. Bond, Medical Department

February 8, 1967

64. The Rise and Stability of the Earth's Atmosphere Lloyd Berkner, Southwest Center for Advanced Studies March 8, 1967

65. The Nature of the Lunar Surface Thomas Gold, Cornell University

April 5, 1967

66. Looking at Matter With Particles, BNL 50059 Harry Palevsky, Physics Department

Mary 24,1967

67. Mechanisms of Oxidation-Reduction Reactions Norman Sutin, Chemistry Department

June 21, 1967 


\section{LIST OF BROOKHAVEN LECTURES}

(Those with BNL numbers have been published or are in press)

1. Radioastronomy and Communication Through Space, BNL 658

Edward M. Purcell, Physics Department

November 16, 1960

2. Current Ideas on the Endocrine Regulation of Cellular Processes, BNL 685

Irving Schwartz, Medical Department

December 14,1960

3. Inside the Protein Molecule, BNL 649

Werner Hirs, Biology Department

January 11,1961

4. Nuclear Chemistry Research With the Cosmotron Gerhart Friedlander, Chemistry Department

February 15,1961

5. Neutron Physics Of and With the High Flux Beám Research Reactor, BNL 664 Herbert Kouts, Nuclear Engineering Department

March 15, 1961

6. High Energy Accelerators, BNL 747

Ernest Courant, Physics Department

April 12, 1961

7. Disclocations in Crystal Lattices George H. Vineyard, Physics Department

May 17, 1961

8. The History of Cosmic Rays and Meteorites, BNL 779

Oliver A. Schaeffer, Chemistry Department

June 14,1961

9. The Physics of Semiconductor Radiation Detectors, BNL 699

G.L. Miller, Instrumentation and Health Physics Department

September 27, 1961

10. Theory of the Gene, BNL 739

Milislav Demerec, Biology Department

October 18,1961

11. Fundamental Particles of Physics

Maurice Goldhaber, Director, Brookhaven National Laboratory

November 15,1961

12. Excessive Salt Intake and Hypertension: A Diefary and Genetic Interplay, BNL 733 Lewis K. Dahl, Medical Department

December 13, 1961

13. Galaxies, BNL 710

Otto Struve, National Radio Astronomy Observatory January 17,1962

14. A Computer Learns To See, BNL 725

Paul Hough, Physics Department

February 14, 1962

15. Wet Electrons - The Radiation Chemistry of Water A.0. Allen, Chemistry Department

March 14, 1962

16. Fundamental Studies of Radiation Damage in Graphite, BNL 745

Donald G. Schweitzer, Nuclear Engineering Department

April 17, 1962

17. The Role of the Cell Nucleus in Determining Radiosensitivity, BNL 766 Arnold H. Sparrow, Biology Department

May 16, 1962

18. Accelerators of the Future, BNL 741 John P. Blewett, Accelerator Department
19. The Renewal of Cells and Molecules. - The Fountain of Youth Walter L. Hughes, Medical Department

September 19, 1962

20. A Neutron's Eye View of Magnetic Materials Julius M. Hastings, Chemistry Department

October 17, 1962

21. Landscaping the Groves of Academe R.C. Anderson, Director's Office

November 14, 1962

22. Chemical Communication Systems in the Cell Henry Quastler, Biology Department

December 12, 1692

23. Neutrino Physics, BNL 787

Leon M. Lederman, Physics Department

January 9,1963

24. The Use and Misuse of the Atmosphere, BNL 784 Maynard E. Smith, Instrumentation and Health Physics Department

February 13,1963

25. The Nucleus Today Denys Wilkinson, Physics Department

March 6, 1963

26. Trace Metals: Essential or Detrimental to Life, BNL 828 George C. Cotzias, Medical Department

April 10, 1963

27. The Early Days of the Quantized Atom Samuel A. Goudsmit, Physics Department

May 15,1963

28. Catalysis in Life and in the Test Tube Daniel E. Koshiland, Jr., Biology Department

June 19,1963

29. Collisions of "Elementary" Particles With Protons at High Energies Samuel J. Lindenbaum, Physics Department

September 25, 1963

30. Chemistry of Isotopes, BNL 870 Jacob Bigeleisen, Chemistry Department

October 16, 1963

31. The Nuclear Reactor Comes of Age, BNL 838 Jack Chernick, Nuclear Engineering Department November 13, 1963

32. Radio Galaxies David Heeschen, National Radio Astronomy Observatory

January 15,1964

33. The Impact of Isotopic Tracers on Physiological Concepts, BNL 857 James S. Robertson, Medical Department

February 12,1964

34. The Biology of Aging, BNL 854 Howard J. Curtis, Biology Department

March 18, 1964

35. The Problem of Development, BNL 976 Ernst W. Caspari, University of Rochester April 15, 1964

36. Bubble Chambers: Instruments for High Energy Physics Experiments William B. Fowler, Physics Department

May 6, 1964

37. Bubble Chamber Experiments - Alpha to Omega Minus Nicholas P. Samios, Physics Department

May 20,1964 